\title{
SEPSIKA-SOOD EESTI NSV-S
}

\section{H. TRASS}

Viimaste aastate jooksul on kogunenud kaunis suur teaduslik materjal Eesti NSV soode mitmesuguste omaduste - taimkatte, turbalasundi, geneesi, kasutamisvõimaluste jm. - kohta. See materjal, täiendatuna ja üksikasjaliselt läbitöötatuna, vőimaldab juba lähematel aastatel asuda koostama üldist monograafilist ülevaadet Eesti soodest. Enne seda on aga vajalikud mitmesugused eriküsimusi käsitlevad sooteaduslikud tööd - nii geobotaanilised, palinoloogilised, geograafilised, stratigraafilised kui ka majanduslikud. Sealjuures tuleb märkida, et Eesti soodel on mitmesuguseid selliseid omadusi ja tunnuseid, mis puuduvad või on haruldased meie naaberalade soodel. Nende ridade kirjutaja, töötades Lääne-Eesti madalsoode taimkatte uurimisel, pööraski siin suuremat tähelepanu peamiselt meie soodele omastele taimkatte-ühikutele. Ei ole kahtlust, et Lääne-Eesti madalsoode taimkattele annavad ilme lubjalembesed taimekooslused - pruuni sepsika (Schoenus ferrugineus), lubika (Sesleria coerulea), ääristarna (Carex Hostiana), raudtarna (C. Davalliana) ja mōnede teiste fütotsönoosid. Pruuni sepsika fütotsönoosid, mis on Lääne-Eesti madalsoodel kõige laialdasemalt levinud, köitsid autori suuremat tähelepanu ning 1950.-1955, a. suvede jooksul kogunes nende kohta ligi 200 geobotanilist kirjeldust. Peale selle teostati turbalasundi puurimisi ja koguti proove turba mōnede omaduste (koosseis, lagundumisaste, tuhasus, $\mathrm{pH}$, lubjasisaldus) laboratoorseks määramiseks. Need materjalid koos kirjanduse ja käsikirjaliste tööde andmetega on käesoleva kirjutise faktiliseks aluseks,

\section{Pruuni sepsika levik}

Pruun sepsikas kuulub taimegeograafiliselt Euroopa elementi. Ta pea-levikuala asub Kesk- ja Lääne-Euroopas - Saksamaal, Inglismaal, Prantsusmaal, Sveitsis, Austrias. Nendest maadest lõuna ja ida poole väheneb selle taime esinemissagedus mõnevõrra, kuid Poolas ja Ungaris esineb teda siiski veel päris ohtralt. Nōukogude Liidus on see taim levinud Ukrainas, Valgevene NSV-s, Balti vabariikides ja huvitava osa-areaalina Baškiiri ANSV-s [ $\left.{ }^{1}\right]$. Eesti NSV naaberaladel on selle taime levik järgmine: Lätis maa lääneosas, kus moodustab kohati suuri kogumikke, näit. Kanjeris järve ja Raganu soo servas Tukumsi rajoonis $\left(\left[^{18}\right]\right.$ lk. 454 - esineb Lätis neljas kohas); Pihkva oblastis kohati suurte kogumikena Irboska ümbruse madalsoodel $\left.\left({ }^{2}\right] \mathrm{lk} .202\right)$; Leningradi oblastis vaid harva, keskosas ([ $\left.{ }^{3}\right]$ lk. 181); Karjala ANSV-s väga harva, ainult taimegeograafilises rajoonis Karelia Onegensis $\left(\left[{ }^{12}\right]\right.$ lk. 217); Murmanski oblastis ainult ühes kohas oblasti edelanurgas Kantalahti ligidal ( $\left[{ }^{4}\right]$ lk. 43); Soomes maa edela- ja lääneosas harva $\left[{ }^{17}\right]$; Rootsis maa idaosas $\left[{ }^{9}\right]$, Ölandi ja Gotlandi saartel $\left[{ }^{14}, 26\right]$. Võrreldes naabermaadega paistab silma pruuni sepsịka suur ohtrus ja esinemissagedus Eestis. Pōhja-Euroopas esineb ta ainult Gotlandi ja Olandi saarel samasuguse sagedusega kui Lääne-Eestis.

Vōttes aluseks prof. Lippmaa $\left.{ }^{20}\right]$ taimegeograafilise jaotuse, antakse pruuni sepsika praegune levikupilt Eestis joonisel 1, mille koostamisel on kasutatud kirjanduslikke, käsikirjalisi, herbaar- ja isiklike vaatluste materjale, samuti mōningaid levikukatalooge.

Lääneranniku ja sa arte 1 ä än e-a lava 1 dk ond (Emoc). Lääne-Saaremaa madalsoodel ülisage, Lääne-Hiiumaal esineb harvemini; kasvab ka väiksematel saartel, nagu Abruka ja Vilsandi.

Lääneranniku ja sa a rte ida-a lavaldkond (Emor). Kogu idapoolsel Saaremaal väga harilik, leitud igal läbiuuritud madalsool; Muhus harvem, on märgitud lōunaranniku ligidal Vởikülas ja Muhu soos; Ida-Hiiumaal mitte harilik, samuti Vormsil $\left(\left[{ }^{10}\right]\right.$ lk. 29, $\left[{ }^{11}\right]$ lk. 52, $\left[{ }^{8}\right]$ lk. 56); mandri lääne- ja looderanniku madalsoodel ja niisketel soostuvatel lubjarikastel niitudel harilik. 
Loode-Eesti valdkond (Einf). Selle valdkonna läänepoolses osas on pruun sepsikas tähtsaim madalsoode taim, esinedes tihti ja ohtralt peaaegu kõikidel madalsoodel; harveneb ida suunas; valdkonna idapiir on selle taime üllatavalt täpseks massilise esinemise piiriks; viimane läbib järgmised punktid: Aruküla - Alavere Kose - Juuru - Kehtna - Kergu - Are.

Vahe-Eesti valdkond (Eint). Selles valdkonnas on pruun sepsikas väga haruldane; on teada mōned leiukohad valdkonna lõunaosast ja piirialalt Pandivere valdkonnaga.

$\mathrm{P}$ a ndivere valdk ond (Esup). Siin on pruuni sepsikat leitud mitmest üksteisest küllalt kaugel asuvast kohast. Väljakujunenud ühingu dominandina esineb ta laialdasel alal Ambla jõe ääres lubjarikkal madalsool $\left(\left[{ }^{22}\right] \mathrm{lk} .108\right)$ ja Kurtna järve ääres.

Alut a g use valdkond (Alt). Selles valdkonnas on pruun sepsikas haruldaseks liigiks, seni on teada 3 leiukohta (Jônga, Varesmetsa, Mustaladva).

L ahkme-Eesti valdkond (Emed). Siin on pruuni sepsikat leitud laialipaisatuna mitmes kohas, rohkem aga valdkonna idaosas.

$\mathrm{Kagu}-$ Eesti valdkond (Eor). Selles valdkonnas esineb pruun sepsikas väga harva, praegu on teada ainult 2 leiukohta valdkonna pōhjaosast (Kurista ja Puka).

Pruun sepsikas moodustab sageli iseseisvaid suuri kogumikke, seda ka oma areaali serva-aladel ja osa-areaalidel. Tugevate edifikaatorlike võimete ja kaunis laialdase leviku tōttu on tema järgi nimetatud mitmesuguseid vegetatsiooniühikuid: Sernander ( $\left[{ }^{25}\right]$ Ik. 35) - Schoenus-formatsioon, du Rietz ([ $\left.\left.{ }^{7}\right] 1 \mathrm{k} .41\right)-$ Schoenus-assotsiatsioon, Almquist $\left(\left[{ }^{3}\right]\right.$ lk. 145$)-$ Schoenus-sootüüp, Booberg $\left(\left[{ }^{4}\right] \mathrm{lk} .74\right)$ - Schoenus ferrugineus
- Drepanocladus intermedius - Campylium stellatum ${ }^{\prime} \mathrm{i}$ sotsiatsioon. Kesk-Euroopa geobotaanikud eraldasid assotsiatsiooni Schoenetum schoenetosum ferruginei ning kirjeldasid seda mitmes töös $\left[{ }^{15}, 16,{ }^{30},{ }^{33}\right]$. Jälgides kirjanduse andmete pōhjal sepsika-soode levikut nähtub, et laialdasemalt ning väljakujunenumana esinevad nad Kesk- ja Lääne-Saksamaal, Sveitsis, Olandil ja Gotlandil ning Eestis.

Eesti NSV-s levivad suuremad sepsika-sood ecskätt maa lääneosas ja läänepoolsetel saartel. Nagu nähtub joonisest 1, esineb pruun sepsikas dominandina suuremaid kogumikke moodustades peamiselt Saaremaal, Loode- ja Lääne-Eestis. Siin on mitmeid soid, kus sepsika fütotsönoosid moodustavad peamise osa taimkattest, haarates enda alla ligi poole soo üldpindalast (Piila-Eikla, Pahila, Turvalepa jt.). Ida pool on märgitud suuremaid sepsika-soid Ambla jōe luhal, Kurtna järve ääres ja Jõgeva ligidal.

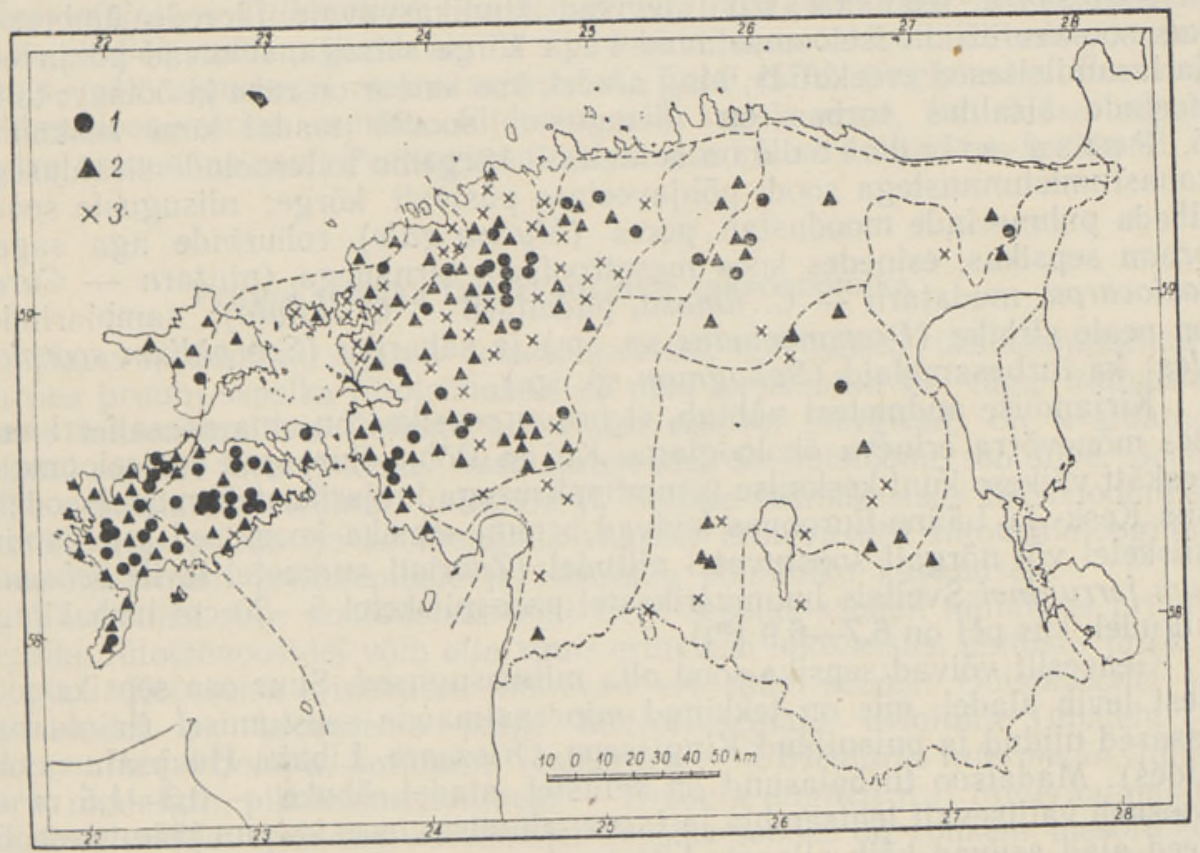

Joon. 1. Pruuni sepsika levik Eesti NSV-s (1-esineb väljakujunenud ühingut moodustavana, 2 - esineb väiksemate kogumikena, 3 - esineb üksikute eksemplaridena). 
Peale pruuni sepsika esineb Eestis hoopis harva mustjas sepsikas (Schoenus nigricans) Praegu asuvad selle taime püsivamad leiukohad Saaremaal Kaanda järve soostunud kaldal (klassikaline leiukoht; siit on seda taime kogunud F. Schmidt, K. R. Kupffer jt.) ja Kuusnōmme mererannikul ning Hiiumaal Heistesoos. Tema püsimine mitmetes teistes kunagistes leiukohtades (Kasti, Rootsiküla, Audru) on küsitav. Mustjas sepsikas moodustab väga harva iseseisvaid kogumikke, enamasti esineb ta koos pruuni sepsikaga, andes sellega ka värdasid (neid leidsime kaunis ohtralt Saaremaal Lümanda Suurisoos).

\section{Sepsika-soode tüpoloogia ja genees}

Pruuni sepsika kasvukohtadeks on peamiselt mitmesugused lubjarikaste madalsoode tüübid (nendelt on umbes $80 \%$ kõikidest selle taime leidudest). Harva võib seda taime leida soostuvatelt niitudelt ja siirdesoodelt. Saaremaal oleme teda mõnikord leidnud ka mereranniku taimkattes (näit. Kuusnõmme poolsaarel) või savikatel järvekallastel (Järise ja Koigi järve ääres). Mineraalmaa taimekooslustes kasvab pruun sepsikas väga harva - teda leitakse vahel niisketel lubjarikastel niitudel ja puisniitudel.

Sootüüpide hulgas eraldame järgmisi, kus rohurinde dominandiks on pruun sepsikas $\left[{ }^{23},{ }^{27}\right]$ : 1 . S e p s i ka-pä r is m a d a l s o o d paiknevad laialdaselt veelahkme-aladel, kus madalsood on enamasti tekkinud mineraalmaa soostumise teel; harva tekivad nad järvede või merelahtede soostumise teel; veerežiimi iseloomustab püsiv kõrge põhjaveetase; toitesoolade sisaldus turbas on kõrge; levinud väga laialt Lääne-Eestis. 2. S e p s i k a - a 11 i k as o o d paiknevad madalate või kõrgemate nõlvade jalameil, kus tekivad allikate ümbruses; levinud Lääne-Saaremaal, Sõrves, harva mandril, sealjuures ka maa idaosas (Jõgeva ligidal); veerežiimi iseloomustab surveline põhjavesi; toitesoolade sisaldus turbas keskmine kuni kõrge. 3. S e p s i k a $1 \mathrm{u}$ h a s o o d esinevad väga harva mõnede jõgede luhtadel (Ambla); veerežiim - üleujutused, toitesoolade sisaldus turbas keskmine kuni kõrge. 4. Sepsika-õõts i ks o o d levivad kinnikasvavate järvede ümbruses, kus soo veerežiimi iseloomustavad väga kõrge seisuga, liikuvad põhjaveed ja lasundisisesed «veekotid», ning aladel, kus kamar on rabe ja õõtsuv; toitesoolade sisaldus turbas on niisugustel soodel madal kuni keskmine. 5. P o r s a - s i i r d e s o o d on suhteliselt kõrgema toitesoolade sisaldusega rabastumistunnustega sood; põhjaveetase püsivalt kõrge; niisuguste soode tiheda puhmarinde moodustab porss (Myrica gale), rohurinde aga sageli pruun sepsikas, esinedes koos mesotroofsete tarnadega (niittarn - Carex lasiocarpa, mudatarn - C. limosa, pudeltarn - C. inflata); samblarindes on peale sirbiku (Drepanocladus sp. sp.) ja säbariku (Scorpidium scorpioides) ka turbasamblaid (Sphagnum sp. sp.).

Kirjanduse andmetest nähtub, et pruun sepsikas on oma areaali eri osades mõ̃nevõrra erineva ökoloogiaga. Kui ta Põhja-Euroopas on iseloomulik eeskätt väikese kuni keskmise lasundipaksusega lubjarikastele madalsoodele, siis Kesk- ja Lääne-Euroopas levivad pruuni sepsika kooslused sagedamini niisketel või nõrgalt soostuvatel niitudel (Zobristi andmetel levib Schoenetum ferruginei Šveitsis huumusrikastel parasniisketel $5-20 \mathrm{~cm}$ turbakihiga niitudel, kus $\mathrm{pH}$ on $\left.6,7-6,9\left[{ }^{33}\right]\right)$.

Geneesilt võivad sepsika-sood olla mitmesugused. Suur osa sepsika-soodest levib aladel, mis on tekkinud mineraalmaade soostumisel (laialdased tasased niidud ja puisniidud Kingissepa, Orissaare, Lihula, Haapsalu rajoonides). Madalsoo turbalasund on sellistel aladel õhuke $-0,3-1,5 \mathrm{~m}-$ koosneb valitsevalt lehtsambla ja tarna, alumises osas ka puu jäänustest. Et need alad asuvad kõik allpool Litorina-transgressiooni maksimaalset kõrgust, võib arvata, et nende aeglane soostumine algas peale Litorina-mere taandumist. Primaarseks taimekoosluseks võis siin olla lubika-puisniit, mis 
veerežiimi muutudes ja turbakihi ladestumisel vahetus väiketarna-puisniiduga (hirsstarn - C. panicea, harilik tarn - C. Goodenowii), see aga omakorda sepsika-madalsooga. Niisuguste soode turbalasundi alumistes kihtides ei leidnud me pilliroo jäänuseid. Seepärast võib arvata, et siin on puudunud tugevat veestumist nõudvad pilliroo- ja suurtarnade (luhatarna - C. elata, niittarna) kooslused. Väga huvitavaks probleemiks on pruuni sepsika fütotsönooside vanus Lääne-Eesti madalsoodel. Arvestades, et sepsika pähikud ja lehetuped on lagundumisele hästi vastupidavad, vôib pidada selle taime sügavamal turbalasundis asuvaid leide kokkulangevateks tema ilmumisajaga Eesti soodele. Turbaproovide analüüs näitab, et pruuni sepsika vähem või rohkem lagundunud jäänused levivad enamasti madalsoo turbalasundi kõige ülemistes kihtides, $0-50 \mathrm{~cm}$ sügavusel, ainult mõne korra leidsime neid $50-70 \mathrm{~cm}$ sügavusel ja 2 korda $80-90 \mathrm{~cm}$ sügavusel (Pahila soos, lasundi üldpaksus puurimiskohas $1,40 \mathrm{~m}$ ). See näitab, et pruuni sepsika fütotsönoosid on Eesti NSV madalsoodel suhteliselt noored. Millisel kliimaperioodil nad ilmusid ning milline on nende absoluutne vanus Eestis, seda on praegu raske öelda, sest puuduvad veel sepsika-soode palinoloogilised analüüsid. Võib arvata, et nende massiline levimine Eesti soodele toimus keskmise holotseeni lõpus.

Järvede ja merelahtede kinnikasvamisel tekkinud soodel levivad pruuni sepsika fütotsönoosid aladel, kus turbalasundi alumistes kihtides esinevad körkja- ja pilliroo-turbad, neist ülevalpool tarna-lehtsambla-, lehtsamblatarna-, pilliroo-tarna-, tarna-pilliroo-, puu-tarnaturvas, ning alles siis võib turbas (enamasti koos tarnade ja lehtsammalde jäänustega) leida sepsika jäänuseid.

Kirjeldatud sepsika koosluste suktsessiooniline järgnevus ühtib suurel määral kirjanduse andmetega. Sveitsi soodel toimub näiteks Messikommeri $\left(\left[^{24}\right]\right.$ lk. 304) järgi niisugune vahetuste rida: Plankton $\rightarrow$ Limnaetum $\rightarrow$ $\rightarrow$ Scirpeto-Phragmitetum $\rightarrow$ Caricetum elatae $\rightarrow$ Schoenetum $\rightarrow$ Trichophoretum alpini $\rightarrow$ Callunetum. Eestis ei leia aga kinnitust Messikommeri väide, et Schoenetum ilmub ainult siis, kui inimene takistab niitmise, karjatamise või raiumisega metsa arenemist. Eesti NSV tingimustes ilmuvad suktsessiooniseerias sepsika fütotsönoosid sageli enne, kui üldse algab metsa arenemine sool. Peatingimuseks on siin küllalt lubjarikas keskkond.

\section{Pruuni sepsika taimekoosluste taksonoomika}

Alates möödunud sajandi teisest poolest, mil hakati üksikasjalisemalt uurima pruuni sepsika fütotsönoose, on neid kirjeldatud ka väga mitmesuguste taksonoomiliste ühikute all. Nagu eespool märgitud, on eraldatud pruuni sepsika formatsioone, assotsiatsioone, sotsiatsioone, sootüüpe, peale selle assotsiatsioonirühmi, ühinguid jt. Selline mitmekesisus taksonoomilistes ühikutes sõltub eri koolkondade vaadete erinevustest fütotsönoloogilise klassifikatsiooni printsiipidele ja iseäranis põhiühiku küsimusele.

Võrdlemisi suur analüüsimaterjal Eesti sepsika-soodelt näitab, et pruuni sepsika fütotsönoosidel võib olla suuri erinevusi koosseisus, ehituses ja ökoloogias. Koosseisu erinevused ilmnevad eri tüüpi soodel. Oõtsiksoodel ja luhasoodel on koosseisus palju hüdrofiilsemaid helofüüte (ubaleht Menyanthes trifoliata, keskmine vesihernes - Utricularia intermedia, luhatarn, mudatarn, pikalehine huulhein $\rightarrow$ Drosera anglica jt.). Mineraalmaade soostumisaladel tekkinud kuivematel sepsika-soodel on rohkem mesofiilsemaid liike, nendele ilmub ka mitmeid niidutaimi (aaslina - Linum catharticum, lubikas, maamõōl - Geum rivale, pääsusilm - Primula farinosa, madal mustjuur - Scorzonera humilis jt.). Ehituse erinevused väljenduvad 
koosluste rindelises struktuuris; osa pruuni sepsika kooslusi on lihtsa ehitusega - esineb põõsarinne ja rohurinne, teised rinded on nõrgalt esindatud või puuduvad hoopis. On aga kooslusi, kus rindeid on rohkem ning nad on selgesti välja kujunenud. Oõtsiksoodes esinevates pruuni sepsika kooslustes on näiteks väga tugevasti välja arenenud samblarinne säbarikust. Ökoloogilised erinevused vỗivad olla samuti võrdlemisi suured. Sepsika kooslused kasvavad nii õhukeselasundilistel ja võrdlemisi kuivadel (pōhjavesi 20$60 \mathrm{~cm}$ sügavusel) kui ka keskmise lasundipaksusega ja vesistel soodel.

Kerkib küsimus - kuidas süstematiseerida niisuguseid mitme tunnuse poolest erinevaid sepsika fütotsönoose? Kas on õigus neil geobotaanikutel, kes kõik sepsika fütotsönoosid loevad ühe assotsiatsiooni alla, või tuleb nende hulgas eraldada mitu assotsiatsiooni, vastavalt fütotsönooside erinevustele? Siin kohtume fütotsönoloogilise süstemaatika vana probleemiga põhiühiku mahu küsimusega. On ju fütotsönoloogilises kirjanduses antud kümneid assotsiatsiooni määranguid, mis erinevad üksteisest eeskätt mahult. Mitmete määrangute võrdleva rakenduse järgi tulime otsusele, et assotsiatsiooni ehk fütotsönooside tüübi määravad järgmised tunnused: 1) teatud liigiline koosseis, 2) karaktertaimed, mis võivad esineda dominantidena või saatjatena, 3) ehitus, 4) keskkonnatingimused, 5) küllaldane esinemissagedus ja kogumike küllaldane suurus kindlas taimkattetüübis, 6) fütotsönooside suktsessiooniline samaväärsus. Nendele tunnustele vastavaid assotsiatsioone on ükskõik missuguses taimkattetüübis hoopis vähem kui dominantide rindeliste kombinatsioonidena eraldatud ühikuid (mida oleks õigem järjekindlalt nimetada sotsiatsioonideks). Lääne-Eesti madalsoode taimkattes on näiteks paarisaja sotsiatsiooni ümber, aga assotsiatsioone ainult $33\left[{ }^{27}\right]$.

Pruuni sepsika fütotsönooside hulgas oleme eraldanud kaks assotsiatsiooni: Schoenetum ferruginei drepanocladiosum ja Schoenetum ferruginei scorpidiosum. Esimene neist on levinud suhteliselt kuivematel lubjarikkamatel ja õhemalasundilistel madalsoodel, teine - kõrgema põhjaveetasemega, tüsedamalasundilistel madalsoodel. Nende assotsiatsioonide põhimised tunnused on toodud tabelis $1 \mathrm{k} .139$.

\section{Pruuni sepsika taimekoosluste ehitus ja koosseis}

Taimekoosluste ehituse ja koosseisu seaduspärasuste selgitamiseks rakendasime sünuuside meetodit. See seisneb fütotsönooside kindlapiiriliste, struktuurilt ja ökoloogialt eraldatud osade - sünuuside - analüüsis. Sünuusiks on eelkõige iga rinne, pealeselle aga samblike kogumikud puude tüvedel ja okstel, samblad kividel ja teised nn. rindevälised rühmitused [19, 21, 28, $\left.{ }^{31}, 32\right]$.

Sünuusilisteks klassifikatsiooni-ühikuteks on ühing ja unioon. Uhing on sünuusiline põhiühik, millesse ühendatakse kõik koosseisult, ehituselt ja ökoloogialt sarnased ja samasse tüüpi (üks ja sama rinne või rindeväline rühmitus) kuuluvad sünuusid. Unioon on laiem ühik, millesse kuuluvad koosseisult (eeskätt karakterliikide poolest), ökoloogialt ja geneesilt sarnased ühingud.

Pruuni sepsika fütotsönooside koosseis ja ehitus ühingute kaupa on järgmine.

P u u rinde ühingutest esinẹb pruuni sepsika kooslustes sageli sookase (Betula pubescens) ühing. See koosneb 5-15 m kõrgustest puudest, millede tüve diameeter on $4-18 \mathrm{~cm}$, puude arv hektaril 50-300 (harva kuni 500). Sookask esineb peamiselt sepsika-pärismadalsoodel, õõtsiksoodest ainult vanematel, tüsedamalasundilistel, rabastumistunnustega soodel. Väga harva märgiti sepsika-soodel hariliku männi (Pinus silvestris) ühingu fragmente. Kokku on sepsika-soode taimekoosluste puurindes märgitud 5 puuliiki. 
Schoenetum ferruginei drepanocladiosum

Liikide arv rohurinde ana- $9-20 \quad(15,2)$

lüüsides ja liikide arvu keskmine

Karakterliigid

Samblarinne

Sootüübid

Keskkonnatingimused

a) turbalasund

b) pōhjavesi

c) valitsev turbaliik

d) tuhasisaldus (30 cm

e) lubjasisaldus $(\mathrm{CaO} \%)$

f) $\mathrm{pH}$
Schoenus ferrugineus, Myrica gale, Pinguicula vulgaris, $P$. alpina, Epipactis palustris, Tofieldia calyculata, Drepanocladus intermedius, Campylium stellatum

Drepanocladus intermedius'e ja Campylium stellatum'i ühing, sageli on see hõre

Sepsika-pärismadalsood, sepsika-allikasood (ka märjad soostuvad lubjarikkad puisniidud)

\section{$0,3-1,5 \mathrm{~m}$}

$20-60 \mathrm{~cm}$

lehtsambla-tarna-, tarna-lehtsambla- või puu-tarna-lehtsamblaturvas

$9,8-13,8$

$2,8-4,2$

$5,68-7,12$
Schoenetum ferruginei scorpidiosum

$6-15(10,5)$

Schoenus ferrugineus, Mifrica gale, Pinguicula vulgaris, P. alpina, Drosera anglica, Scorpidium scorpioides

Scorpidium scorpioides'e ühing, alati tihe ja vohav

Sepsika-õōtsiksood, porsasiirdesood

\section{$0,9-2,5 \mathrm{~m}$}

$5-30 \mathrm{~cm}$

tarna-pilliroo-, pilliroo-tarnavôi puu-tarna-pillirooturvas

$9,4-11,0$

$1,2-4,1$

$5,12-6,52$

Põõs a rinde ühinguid märkisime kaks - tavalisem on sookase-paakspuu (Betula pubescens - Rhamnus frangula) ühing, harva esineb tuhkurpaju (Salix cinerea) ühing. Põõsarinde ühingud ilmuvad suktsessioonireas varem kui puurinde ühingud - juba kaunis noortel kujunevatel õõtsiksoodel. Põõsarindes märgiti kokku 11 liiki.

$\mathrm{Puhm}$ arindes esineb väga karakteerne porsa ühing. See koosneb eeskätt ühingu nimiliigist, ainult harva seguneb temasse hundipaju (Salix rosmarinifolia), lapi paju (S. lapponum), kanarbik (Calluna vulgaris), sookail (Ledum palustre).

Rohurindes esinevat pruuni sepsika ühingut iseloomustavad järgmised andmed. Ohingu minimaalruumiks on $4-6 \mathrm{~m}^{2}$. 198-s analüüsis märgiti kokku 81 taimeliiki. Liikide arv analüüsides oli $6-20$, keskmine $-11,8$. Liikide hulga mutlikkus on näidatud joonisel 2. Eri analüüside liigilise koosseisu kvantitatiivsed erinevused selguvad ühtsuskoefitsiendi kasutamisest $\left[{ }^{13}\right]$. Koondtabelis kõrvutiseisvate analüüsipaaride ühtsuskoefitsient kõigub 18-34 vahel, keskmine 20 analüüsipaari kohta on $29 \%$ (lubika ühingus $25 \%$, hirsstarna-hariliku tarna ühingus $28 \%$ ). Niidukooslustes, kus on rohkem uuritud ühtsuskoefitsienti, on see enamasti $33-36 \%$. Ainukeseks $100 \%$ konstandiks on ühingu nimiliik. $\mathrm{X}$ konstantsusklassis $(91-100 \%)$

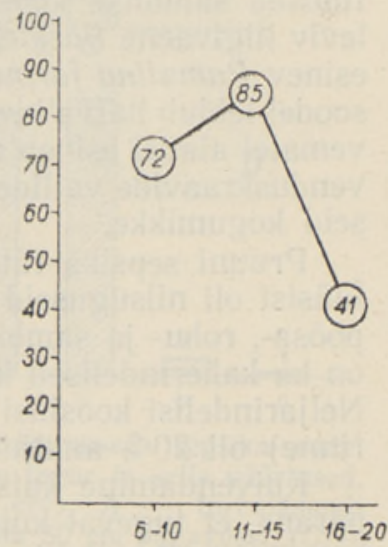

Joon. 2. Liikide arv pruuni sepsika ühingus (rōhtteljel liikide arv, püstteljel analüüside arv). 
esinevad veel sinihelmikas (Molinia coerulea), harilik võipätakas (Pinguicula vulgaris), pääsusilm, lubikas. Ule $50 \%$ konstantsusega on pilliroog (Phragmites communis) (IX) ${ }^{1}$, hirssstarn (IX), tedremaran (Potentilla

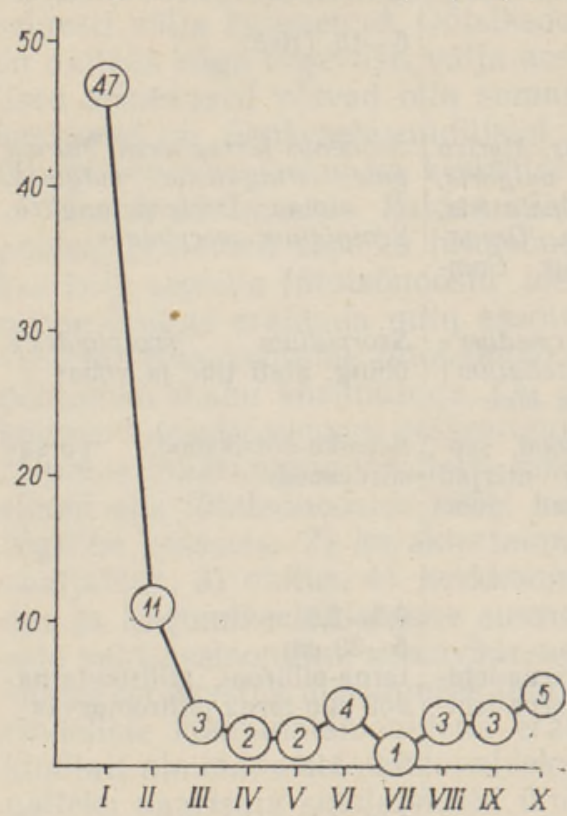

Joon. 3. Pruuni sepsika ühingu konstantsuskōver (rōhtteljel konstantsusklassid, püstteljel liikide arv). erecta) (IX), peetri piibeleht (Succisa pratensis) (VIII), pikalehine mailane (VIII), ubaleht (VIII), soo-neiuvaip (Epipactis palustris) (VII), ädallill (Parnassia palustris) (VI), soo-piimputk (Peucedanum palustre) (VI), niittarn (VI), kahkjaspunane käpp (Orchis incarnata) (VI), lemmelill (Tofieldis calyculata) (V), kollane tarn (Carex flava) (V). Liike, millede konstantsus on $1-50 \%$, on $63(77,8 \%$ ühingu liikide üldarvust), I konstantsusklassi kuulub 47 liiki $(58 \%)$. Konstantsuskõver (joon. 3) näitab, et ühing on võrdlemisi labiilse koosseisuga. Seda põhjustavad mitmesugused välised mõjutused sepsika-soodel — kuivendamine, karjatamine, niitmine. Võrreldes teiste lubjalembeste ühingutega märkame siiski suhteliselt suuremat stabiilsust; näiteks võrreldes lubika ühinguga (120 analüüsi andmetel) on käsiteldavas ühingus 1) veidi vähem liike I konstantsusklassis, 2) rohkem liike kõrgemates konstantsusklassides.

$\mathrm{S}$ a m blarinde ühingutest on pruuni sepsika fütotsönoosides harilikumad keskmise sirbiku ühing ja säbariku ühing. Harva esinevad teravtipu (Acrocladium cuspidatum) ühing, soovildiku (Aulacomnium palustre) ühing. Kõik need on liigivaesed ühingud (liikide arv analüüsides $1-8$, keskmine $3,6)$, koosnedes peamiselt domineerivast nimiliigist. Uldse on sepsika-soode taimekoosluste samblärindes märgitud 26 liiki.

R indevälistest ühingutest esinevad sepsika-soodel mitmed epifüütsed samblike kooslused. Kõige tavalisem on sookase ja männi koorel leviv liigivaene Parmelia physodes'e ühing ning fragmentidena puude okstel esinev Ramalina farinacea - Evernia prunastri ühing. Ohukeselasundilistel soodel leidub harva kividel kähariku (Rhytidiadelphus triquetrus) ühing, kuivematel aladel esineb mikroreljeefi kõrgendikel Cladonia furcata ühing. Kuivenduskraavide vallidel leidub Cladonia deformis - C. cenotea ühingu väikseid kogumikke.

Pruuni sepsika fütotsönoosid on valdavalt kolmerindelised. 198-st analüüsist oli niisuguseid 99 , s. o. täpselt $50 \%$. Kolmerindelistes kooslustes on põõsa-, rohu- ja samblarinne, või puhma-, rohu- ja samblarinne. Sagedased on ka kaherindelised kooslused ( $26 \%$ analüüsidest) rohu- ja samblarindest. Neljarindelisi kooslusi (puu- või põõsarinne ja puhma-, rohu- ning samblarinne) oli $20 \%$ analüüsidest ja vilerindelisi $4 \%$.

Kuivendamine kutsub sepsika-soodel esile suuri muutusi. On seaduspärane, et tugeval kuivendamisel vahetuvad pruuni sepsika kooslused sinihelmika teiskooslustega. Sellega kaasnevad muutused mikroreljeefis (kõrgete mätaste kujunemine), puu- ja põõsarindes (algab võsastumine) $\left.{ }^{29}\right]$. 


\section{Keskkonnatingimused sepsika-soodel}

Nagu juba eespool on märgitud, võivad pruuni sepsika fütotsönoosid levida võrdlemisi mitmesugustel kasvukohtadel — soostuvatel lubjarikastel niitudel ja puisniitudel, pärismadal-, allika-, õotsik-, luha- ja isegi siirdesoodel. Olenevalt sellest võivad ka keskkonnatingimuste näitajad pruuni sepsika taimekooslustes olla mitmesugused ja omada kohati kaunis laiu amplituude. Sealjuures selgub, et eri teguritel on olemas teatud väärtused ja suurused, millede juures pruuni sepsika kooslused esinevad sagedamini, suuremate kogumikena ja paremini väljakujunenult (joon. 4).

Turba 1 a sund i paksus kõigub sepsika-soodel $0,3-2,5$ $\mathrm{m}$ vahel. Fütotsönooside koosseisu alusel saab otsustada turbalasundi paksuse üle. Schoenetum ferruginei drepanocladiosum levib põhiliselt õhemalasundilistel aladel $(0,3-0,8 \mathrm{~m}$, $1,1-1,5 \mathrm{~m})$, Schoenetum ferruginei scorpidiosum tüsedamalasundilistel (2 $\mathrm{m}$ ümber). Ohemalasundilistel aladel on fütotsönooside koosseisus enam mesofiilsussekalduvaid niidutaimi, tüsedamalasundilistel aladel euhelofüüte ja hüdrofiilsemaid liike.

T u r b a li igid võivad sepsika-soode turbalasundites olla mitmesugused. Ohemalasundilistel soodel valitsevad täielikult tarna ja pruunsambla jäänustest turbad mitmesugustes kombinatsioonides, segunedes sageli ka puujäänustega. Limnilise tekkega aladel lisandub neile pilliroogu, mis õotsiksoode lasundis muutub valitsevaks.

Turvaste 1 agundu$\mathrm{mis}$ aste on enamasti $40-$ $60 \%$, harva $30-40 \%$ ja üle $60 \%$. Ka sepsika-soodel avaldub seaduspärasus - väiksematel ja õhemalasundilistel soodel on turba lagundumisaste kõrgem, suurematel ja tüsedamalasundilistel madalam.

Aluskivim võib olla mitmesugune - kõige sagedamini on selleks savi, tihti ka saviliiv või liivsavi, harvemini liiv ja kruus, väga harva paas.

Veerežiim oleneb sootüübist. Veerežiimi erinevused

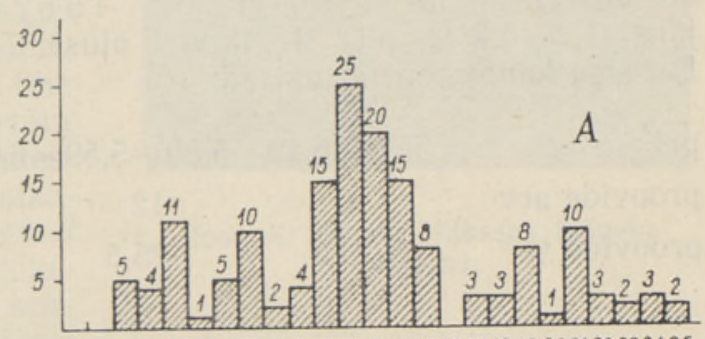

$0,10,20,30,40,50,60,7 Q 80,9101,11,21,31,41,51,61,71,81,92,0212222,32,42.5$
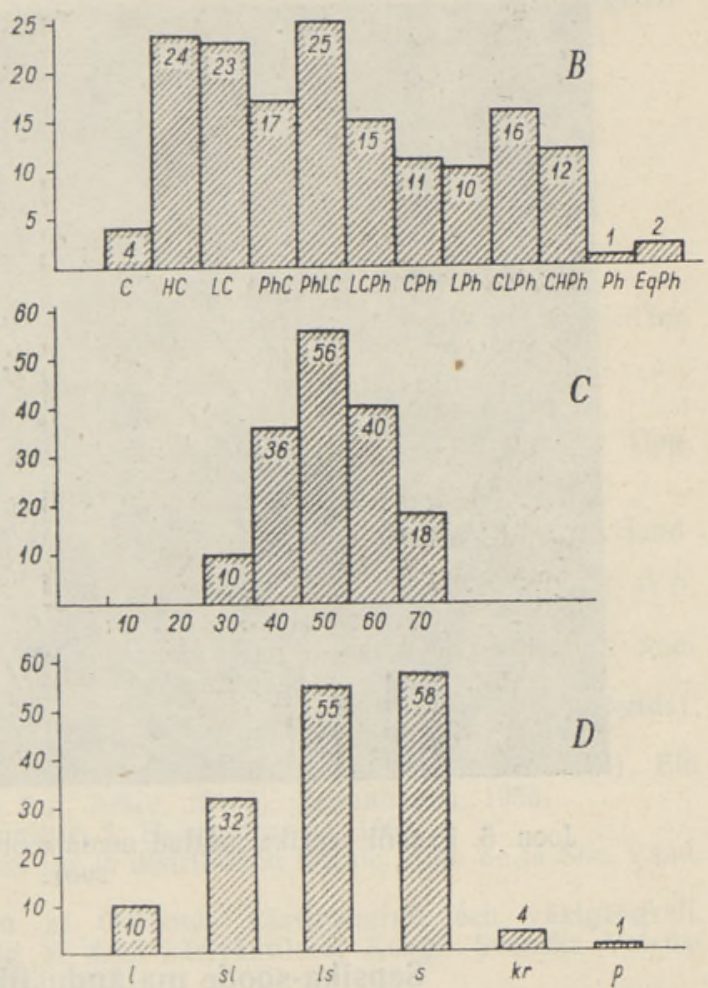

Joon. 4. Keskkonnatingimused sepsika-soodel (rôhtteljel ökoloogiline tegur ja selle väärtused, püstteljel analüüside arv). $A-$ turbalasundi sügavus; $B$ - turbaliik $30 \mathrm{~cm}$ sügavusel $(C-$ tarna, $H$ - lehtsambla, $L$ - puu, $P h-$ pilliroo, $E q$ - osja jäänused); $C$ - turba lagundumisaste $30 \mathrm{~cm}$ sügavusel; $D-$ aluskivim $(l-\mathrm{liiv}$, $s l$ - saviliiv, $l s-$ liivsavi, $s-$ savi, $k r-$ kruus, $p$ - paas). 
allikasoodel (survelised põhjaveed), õõtsiksoodel (liikuvad kõrge seisuga põhjaveed, pinnaveed) ja luhasoodel (üleujutused) mõjutavad ka teiste ökoloogiliste faktorite kujunemist. Väga tähtsat osa etendavad lubjarikastelt mineraalkallastelt soole pealevalguvad veed. Need toovad ohtralt kaasa lubjaühendeid, mis muudavad turbalasundi ülemiste kihtide reaktsiooni. Kõrgete loopealsetega piirneva Täätsi soo turbalasundis (Saaremaal) oli

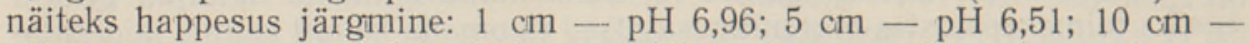
pH 6,01; $30 \mathrm{~cm}-\mathrm{pH}$ 5,84. Põhjavesi (õieti pinnasevesi) asub sepsika-soodel 5-60 cm sügavusel; õotsiksoodel 5-30 cm, pärismadalsoodel $20-60 \mathrm{~cm}$ sügavusel.

Turba tuhasisa $1 \mathrm{dus}$ on sepsika-soodel (30 $\mathrm{cm}$ sügavusel) 20 proovi andmetel $9,4-13,8 \%, 1 \mathrm{ubj}$ as is aldus $(\mathrm{CaO}) 15$ proovi järgi $1,2-4,2 \%$, p H 47 proovi alusel 5,12-7,10. pH-andmed, esitatuna klasside kaupa, on järgmised:

$\mathrm{pH}$

$$
5,00-5,49
$$

$5,50-5,59$

$6,00-6,49$

$6,50-6,99$

$7,00-7,49$

proovide arv 10 12 13 10

proovide $\%$

21,3

25,5

27,6

21,3 4,3

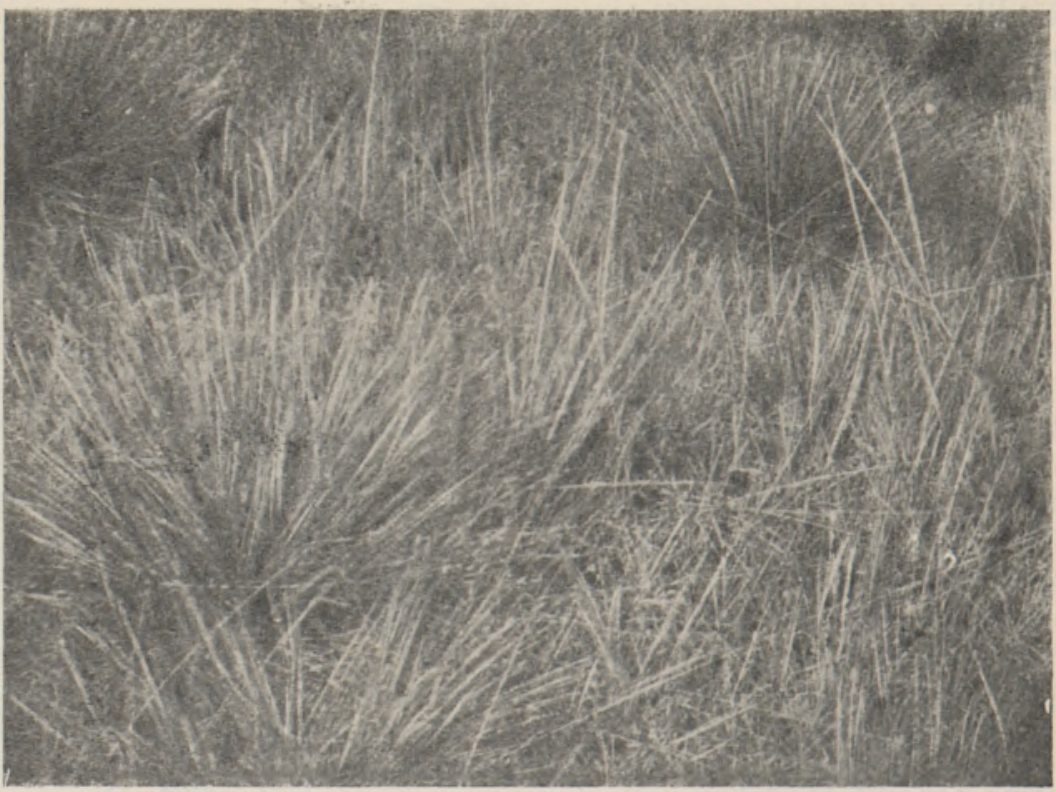

Joon. 5. Pruuni sepsika mättad madalsool (Haapsalu rajoon, Turvalepa soo).

\section{Sepsika-soode majanduslikust tähtsusest}

On harjutud võtma absoluutse tõena, et pruuni sepsika fütotsönoosidega sood kuuluvad viljelusväärtuselt alati kõige paremate hulka. Sealjuures lähtutakse sellest, et sepsikas on lubjalembene liik ja seal, kus ta esineb, peavad järelikult keskkonnatingimused olema taimekasvuks soodsamad. Nagu eeltoodust näha, võivad aga sepsika-sood oma ökoloogialt olla kaunis erinevad, ning selle tõttu võivad olla erinevad ka nende majandusliku kasutuselevõtu 
võimalused. Kahtlemata esmajärgulisse melioratsioonifondi kuuluvad LääneEestis laialt levinud õhukeselasundilised sepsika-pärismadalsood (mis on kaetud assotsiatsiooniga Schoenetum ferruginei drepanocladiosum). Nende soode põllumajanduslikku kasutuselevõttu tuleb kiirendada, sest nende turbalasundi omadused soodustavad kultuurtaimede kasvu (keskmine kuni kõrge lubjasisaldus, nõrgalt happeline kuni neutraalne reaktsioon, hästilagundunud toitaineterikas turvas). Positiivseks jooneks niisuguste soode juures on ka mikroreljeefi suhteline tasasus, puu- ja põõsarinde hõredus. Raskendavaks teguriks võib olla tihe puhmarinne porsast. Kasutuselevõtu seisukohalt komplitseeritud on raskestireguleeritava veerežiimiga sepsikaõõtsiksood (Schoenetum ferruginei scorpidiosum kogumikega). Sepsikaallikasoodel ja -luhasoodel ei ole nen-

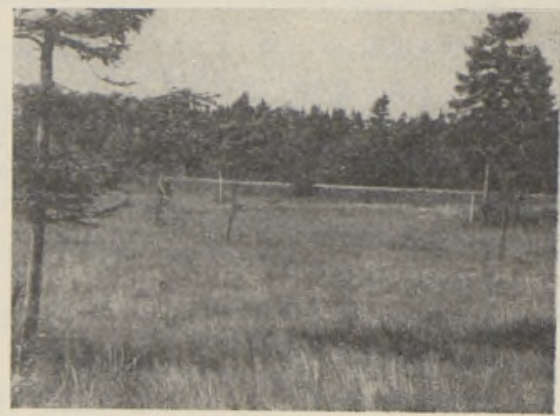

Joon. 6. Sepsika-allikasoo (Jõgeva rajoon) de suhteliselt harva esinemise tõttu erilist majanduslikku tähtsust. Sepsika-siirdesoode ökoloogilised tegurid näitavad, et need sood kuuluvad viljelusväärtuselt teisejärguliste hulka.

\section{KIRJANDUS}

1. Бр а д и с, Е. М., Торфяные болота Башкирин. Автореферат. Киев, 1951.

1. Пуринг Н., Очерк растительности западной части Псковской губ. Тр. С.-Пет. Общ. ес.-исп., 28, 3, 1898.

3. Флора Ленинградской области, І. Ленинград, 1955

4. Флора Мурманской области, II. Ленинград, 1954.

5. A $1 \mathrm{mqui}$ st, E., Upplands vegetation och flora. Acta Phytogeogr. Suecica, I. Upp. sala, 1929.

6. B o o berg, G., Gisselasmoor. Diss. Pfl. biol. Inst. Uppsala, 1930.

7. Du Ri et $z$, D. E., Gotländische Vegetationsstudien. Svenska växtsoc.sällsk. Handlingar, II. Uppsala, 1925.

8. Eklund, O., Beiträge zur Flora der Insel Wormsö in Estland. Acta Soc. pro f. et fl. Fenn., 55, 9. Helsinki, 1929.

9. Eklund, O., Óber die Ursachen der regionalen Verteilung der Schärenflora Südwest-Finnlands: Acta Botanica Fennica, 8. Helsinki, 1931.

10. Gröntved, J., Die Flora der Insel Wormsö (Ein Beitrag zur Flora Estlands). Dansk Bot. Arkiv, 5 (4). Kopenhagen, 1927.

11. Gröntved, J., Botanische Untersuchungen auf der Insel Dagö (Hiiumaa). Ein Beitrag zur Flora Estlands, Dansk Bot. Arkiv, 15 (3). Kopenhagen, 1953.

12. H jelt, H., Conspectus florae Fennicae, I. Helsingforsiae, 1888.

13. J a c c a r d, P., Nouvelles recherches sur la distribution florale. Bull. de la Soc. Vaud. des Sci. Nat., 44, Lausanne, 1908.

14. Johansson, K., Hufereddragen at Gotlands växttopografi och växtgeografi, grundade pa en kritisk behandling af dess kärlväxtflora. Kongl. Svenska Vetenskaps-Ak. Handl., XXIX, 1. Stockholm, 1897.

15. K lika, J., Die Pflanzengesellschaften auf Travertinen bei Stankovany in der Slovakei. Bull. Intern. de l'Acad. des Sci. de Boheme. Prag, 1934.

16. Koch, W., Die Vegetationseinheiten der Linthebene, unter Berücksichtigung der Verhältnisse in der Nordostschweiz. Jahrb. d. St. Natw. Ges. St. Gallen, 1926.

17. Kotilainen, M., Uber die Verbreitung der Meso-Eutrophen Moorpflanzen in Nordfinnland. Suomalais. Tied. akad. Toim., Sarja A, 4, Biol. 17. Helsinki, 1949.

18. Latvijas PSR Flora, I Riga, 1953.

19. L i p p ma a, T., Taimeühingute uurimise metoodika ja Eesti taimeühingute klassifikatsiooni põhijooni. Acta Inst. et Horti Bot. Univ. Tart., III, fasc. 4. Tartu, 1933. 
20. L i p p m a a, T., Eesti geobotaanika pōhijooni. Acta et Comm. Univ. Tart., A. XXVIII, 4. Tartu, 1935.

21. L i p p m a a, T., Areal- und Altersbestimmung einer Union (Galeobdolon - Asperula - Asarum U.) sowie das Problem der Characterarten und der Konstanten. Acta Inst. et Horti Bot. Univ. Tart., VI, fasc. 2. Tartu, 1938.

22. L u n t s, J., Pōhja-Eesti vallseljakute taimkattest I ja II. «Eesti Loodus», V, 3 ja 4. Tartu, 1937.

23. Masing, V. ja Trass, H., Juhend soode geobotaaniliseks uurimiseks. «Abiks Loodusevaatlejale», nr. 23. Tartu, 1955.

24. Messikom mer, E., Verlandungserscheinungen und Pflanzensukzessionen im Gebiete des Pfäffikersees. Festschrift Hans Schinz, Zürich, 1928.

25. S e rn a nder, R., Studier över den Gotländska vegetationens utvecklingshistoria. Akad. avhandl. Uppsala, 1894.

26. Sterner, Flora der Insel Oland. Acta Phytogeograph. Suecica IX. Uppsala, 1938.

27. Trass, H., Lääne-Eesti madalsoode floora ja vegetatsioon (käsikiri TRÛ raamatukogus), 1955.

28. Tr a s s, H., Sünuuside meetodist geobotaanikas. Loodusuurijate Seltsi Aastaraamat, 48. kd. Tartu, 1955.

29. Tr a s s, H., Madalsoode taimkatte muutumisest kuivendamise mõjul. Loodusuurijate Seltsi Aastaraamat, 48. kd. Tartu, 1955.

30. T ü x e n, R., Die Pflanzengesellschaften Nordwest-Deutschlands. Hannover, 1939.

31. V a g a, A., Fütotsönoloogia pōhiküsimusi. Acta et Comm. Univ. Tart., A XXXV. Tartu, 1940.

32. V a g a, A., Eesti NSV soode fütotsönoosidest. Kogumik «Eesti fauna ja floora uurimise küsimusi». Tallinn, 1953.

33. Z o b rist, L., Pflanzensoziologische und bodenkundliche Untersuchung des Schoenetum nigricantis im nordostschweizerischen Mittellande. Beiträge zur geobot. Landesaufnahme der Schweiz, Heft 18. Bern, 1935.

Tartu Riiklik Olikool

Saabus toimetusse

5. XI 1956

\title{
СХЕНУСОВЫЕ БОЛОТА В ЭСТОНСКОИ ССР
}

\author{
X. X. Tpacc
}

\section{Резюме}

Схенус ржавый (Schoenus ferrugineus) - широко распространенное растение и доминант фитоценозов на низинных болотах северной и западной Эстонии (рис. 1). Восточная граница массового распространения этого вида в ӘССР удивительно точно совпадает с восточной границей Северо-западного Эстонского ботанико-географического района ([ $\left.{ }^{20}\right]$ Estonia inferior) и проходит через следующие пункты: Арукюла-Алавере-Козе-Юуру-Кехтна-Кергу-Аре. Восточнее этой границы схенус редеет, а в юго-восточной части республики совсем отсутствует.

Местами произрастания схенуса в ЭССР являются главным образом низинные болота $(80 \%$ всех находок этого растения). Довольно часто встречается он и на заболачивающихся лугах, редко на переходных болотах и на минеральных почвах. Схенус ржавый является доминантом фитоценозов следующих типов болот: схенусовые настоящие низинные болота (очень часто), схенусовые ключевые низинные болота (часто), схенусовые пойменные низинные болота (очень редко), схенусовые топяные низинные болота (довольно часто), восковниковые переходные болота (редко). Анализ торфяной залежи и сукцессионной последовательности фитоценозов схенусовых болот показывает, что схенус ржавый появился на низинных болотах Эстонии относительно недавно: остатки ero найдены на глубине 0,50 см торфяной залежи и только изредка глубже (до 90 см). Можно полагать, что массовое распространение его на эстонские болота произошло в конце среднего голоцена. Схенусовые болота возникли путем заболачивания низинных лугов и лесолугов, а также мелководных водоемов.

Классифицируя схенусовые фитоценозы, мы положили в основу выделения ассоциаций следующие признаки: 1) видовой состав, 2) характерные виды, 3) структуру, 4) условия среды, 5) достаточные размеры и встречаемость фитоценозов, 6) сукцессионную однородность. Схенусовые фитоценозы входят в состав двух ассоциаций - более мезофильной Schoenetum ferruginei drepanocladiosum (встречается главным образом на настоящих низинных болотах) и более гидрофильной Schoenetum f. scorpidiosum (встре- 
чается на топяных и ключевых низинных болотах). Эти ассоциации состоят из ряда (всего 27) социаций (единицы, выделенные только на основе доминантов и структуры).

Схенусовые фитоценозы преимущественно трехъярусные. Самый богатый видовой состав у травяного яруса, в котором отмечен 81 вид растений (изменчивость количества видов показана на рис. 2). Кривая константности (рис. 3) показывает, что синузия из схенуса ржавого отличается лабильностью состава, вызванной различными воздействиями (осушение, пастьба) на растительность.

Глубина торфяной залежи (рис. 4) составляет на схенусовых болотах от 0,3 до 2,5 м, причем господствующими видами торфа являются гипново-осоковые, древесноосоковые и тростниково-осоковые торфы. Степень разложения торфа колеблется обыкновенно между 40 и $60 \%$. Зольность торфа $9,4-13,8 \%$, содержание извести (СаО) $1,2-4,2 \%, \mathrm{pH} 5,12-7,10$. В хозяйственном отношении наиболее ценными являются схенусовые настоящие низинные болота, покрытые ассоциацией Schoenetum $f$. drepanocladiosum, менее ценными - схенусовые топяные низинные болота и восковниковые переходные болота.

Тартуский государственный университет

Поступила в редакцию 5 XI 1956

\section{THE SCHOENUS-SWAMPS IN THE ESTONIAN SSR}

\section{H. Trass \\ Summary}

In the Estonian SSR the Schoenus ferrugineus is mainly spread in the western and northern parts of the country. The boundary of the abundant occurrence of this plant passes through the points Aruküla - Alavere - Kose - Juuru - Kehtna - Kergu - Are, and coincides with surprising exactitude with the eastern boundary of the phytogeographical district of Estonia inferior (Lippmaa, 1935). Schoenus ferrugineus is the constituent of two important associations in Estonia - of Schoenetum ferruginei drepanocladiosum, which occurs on limy swamps and boggy meadows, and of Schoenetum ferruginei scorpidiosum, which occurs on swinging swamps, on swamps abounding in springs and, more rarely, on boggy swamps. The thickness of the peat-layer on Schoenus-swamps is $0,3-2,5 \mathrm{~m}$, the percentage of $\mathrm{CaO}$ in peat $-1,2-4,2$ per cent., $\mathrm{pH} 5,12-7,10$. The phytocoenoses of Schoenus ferrugineus in Estonia are relatively recent and they have probably spread on our swamps in the middle holocene.

Tartu State University

Received Nov. 5,1956 